\title{
Effectiveness of Mindfulness-Based Cognitive-Behavioral Therapy on Relieving Migraine Headaches
}

\author{
Hossein Mansourishad, ${ }^{1}$ Mansoureh Togha,, ${ }^{2, *}$ Ahmad Borjali, ${ }^{3}$ and Reza Karimi ${ }^{4}$ \\ ${ }^{1}$ Master of Clinical Psychology, Allameh Tabatabai University, Tehran, Iran \\ ${ }^{2}$ Professor of Neurology, Headache Department, Iranian Center of Neurological Research, Neuroscience Institute, Tehran University of Medical Sciences, Tehran, Iran \\ ${ }^{3}$ Assistant Professor of Psychology at Allameh Tabatabai University, Tehran, Iran \\ ${ }^{4}$ PhD Student in Clinical Psychology, Shahid Beheshti University of Medical Sciences, Tehran, Iran \\ "Corresponding author: Mansoureh Togha, Professor of Neurology, Headache Department, Iranian Center of Neurological Research, Neuroscience Institute, Tehran University \\ of Medical Sciences, Tehran, Iran. E-mail: toghae@tums.ac.ir
}

Received 2017 April 23; Revised 2017 July 12; Accepted 2017 July 19.

\begin{abstract}
Background: The world health organization has ranked migraine among top 20 disabling diseases. The major adverse effects of migraine headaches on patients and society are an important public health concern. This study aimed to evaluate the effectiveness of mindfulness-based cognitive therapy (MBCT) on reducing the impact of migraine headaches on women.

Methods: In the current study, a quasi-experimental design was applied. In this semi-experimental study, 26 women with migraine were selected via available sampling and were randomly placed into experimental $(n, 13)$ and control (n, 13) groups. All 26 patients were asked to record their experience of headache attacks in terms of frequency, intensity, and duration for 1 month in a headache diary. Subsequently, the experimental group participated in 8 sessions of MBCT (2-hour sessions).

Results: The analysis of covariance (ANCOVA) indicated a significant decline in the mean headache frequency $(\mathrm{P}<0.001)$, duration $(\mathrm{P}<0.001)$, and severity $(\mathrm{P}<0.001)$ in the experimental group.

Conclusions: This trial empirically examined the efficacy of MBCT in the treatment of migraine headaches and showed that MBCT is effective in treating or alleviating migraine headaches. This study could provide a psychological approach for the future treatment of chronic pain to avoid relying on medications alone.
\end{abstract}

Keywords: Mindfulness-Based Cognitive Therapy, Headache, Women

\section{Background}

Migraine is a common disorder, characterized by episodes of moderate to severe throbbing headaches, which are usually unilateral in location (both sides are affected in about $1 / 3$ of attacks). It is accentuated by physical activity and is associated with nausea and/or vomiting, photophobia, and phonophobia (1).

People who experience migraine typically describe it as recurrent headaches with similar symptoms; also, up to one-third of these patients have a preceding aura (migraine with aura) $(1,2)$. The Global Burden of Disease (GBD) survey conducted in 2000 by the world health organization (WHO) recognized migraine as a potentially debilitating disorder all over the world and showed that women suffer from migraines more than men by nearly a 4:1 ratio (3). This finding has been cited repeatedly ever since $(4,5)$.

Migraine treatment can include preventive therapy, aimed at reducing the frequency and severity of migraine attacks, as well as acute therapy, used to abort a migraine attack. In association with the American headache society, the American academy of neurology (AAN) has recently published guidelines for preventive treatments (6). The most recent AAN guidelines for acute treatment were published in 2012 (7).

Notably, the most frequently identified headache trigger is stress $(8,9)$. This suggests the significant potential of psychosocial approaches for headache pain management. A substantial amount of evidence from the literature indicates that cognitive-behavioral therapy(CBT) is efficacious in alleviating headache pain. The benefits of CBT include reduced medication use and decreased headache frequency, intensity, and duration $(10,11)$.

The CBT theory claims that changes in maladaptive cognition, such as pain catastrophizing, can be a key treatment mechanism. Many professional organizations endorse CBT for headache management (12). However, CBT is not universally effective for all individuals, and effect sizes are modest (13); therefore, additional treatment options are needed. A promising trend for chronic pain management is the application of mindfulness-based stress reduction (MBSR) (12). MBSR is associated with significant improvements in pain perception, coping, and affect (14-16).

Theoretically, meditative therapies operate through engendering change in mindfulness and pain acceptance 
(17). Recently, mindfulness-based cognitive therapy(MBCT) has been adapted for the management of headaches (18). Theoretically, MBCT integrates key CBT and MBSR interventional strategies for pain management to directly target change in mindfulness and pain acceptance, which subsequently and indirectly lead to change in maladaptive cognition. Thorough analyses have indicated that individuals receiving MBCT show a significantly larger effect-size improvement in pain interference, catastrophizing, pain acceptance, and self-efficacy, compared to the controls on the waiting list $(8,11,18)$. In this study, our goal was to evaluate the efficacy of MBCT in reducing the severity, frequency, and duration of migraine in women.

\section{Methods}

In this study, a case-control, quasi-experimental, pretest-posttest design was applied. The study population consisted of women suffering from migraine, referred to a headache clinic in Tehran, Iran. Migraine was diagnosed by a specialist, according to the international classification of headache disorders (ICHD-3)-beta (1).

The inclusion criteria were as follows: 1) age, 20 - 40 years; 2) female sex;3) minimum of a 6-month gap between diagnosis and beginning of the study; 4) lack of other psychological therapies over the past 3 months; 5) minimum education of secondary school; 6) no use of medications for anxiety or depression during the past 3 months; 7) minimum of moderate IQ; and 8) migraine without aura according to the ICHD criteria. Those who met the inclusion criteria were recruited between November 2014 and March 2015.

The participants received explanations about the study objectives and reasons for participation. Written informed consents were obtained from all the participants. After completing the baseline assessment, which included 1 month of headache diary recording, 26 patients were randomly and equally assigned to groups via block randomization ( 4 blocks). They were also advised not to use any new medicines or other psychological treatments during the study.

The experimental group participated in eight 2-hour sessions of MBCT, performed by the first author (intervention therapist). The sessions focused on developing nonjudgmental thinking and present-moment awareness of thoughts, emotions, and environment. Homework assignments with the aid of a guided audio file included daily mindfulness meditation practices, such as body scan and breath awareness. Session-by-session description of the protocol is available in the MBCT manual (19).

On the other hand, the exclusion criteria were as follows: 1) severe physical illness; 2) serious neurologi- cal disorders or symptoms of psychosis; 3) unwillingness to continue treatment; and 4) risk of suicidal thoughts and attempts requiring urgent intervention. Posttest assessment, which included 1 month of headache diary recording, was performed in both groups, and all subjects were evaluated based on the scores on the headache diary/questionnaire. Follow-up assessments were performed within 2-month intervals.

\subsection{Data Analysis}

The significance level $(\alpha)$ was assumed to be 5\%. SPSS version 19.0 for windows (IBM Inc., New York, NY, USA) was used to perform the statistical analyses. Analysis of covariance (ANCOVA) was applied to assess differences between patients from independent groups and examine changes in the study variables over time. Headache frequency was determined by calculating the mean number of headache attacks per month.

\subsection{Headache Diary/Questionnaire}

A number of tools from electronic diaries, such as Internet-based online diary, smartphone headache diary, and paper diaries, were developed in order to assist patients in documenting the headache data. However, only a few studies have incorporated the use of smartphone headache diaries in their research protocols $(20,21)$. Therefore, the structured paper headache diary/questionnaire was selected, which tracks the severity, frequency, and duration of migraine.

The headache questionnaire has been applied extensively in previous controlled outcome studies. It was primarily developed by Thomas Budzynski (22) and revised by Leonard H. Epstein and Gene G. Abel (23). The headache index is the mean of all diary ratings over 1 month, providing a measure of overall headache activity. Headache severity (rated on an 11-point Likert scale, ranging from 0 , no pain to 10 , the worst pain you can imagine), number of days with headache per month with minimum of moderate pain (pain rating $\geq 5$ ), and duration of headache were determined in both groups, using the headache diary/questionnaire and compared with each other.

\section{Results}

All participants completed the study, and the main demographic characteristics are presented in Table 1. Among 26 participants who were recruited in this study, 2 had chronic migraine ( $\geq 15$ days of headache per month) and 24 had episodic migraine headaches ( $<15$ days of headache per month). The mean age of the participants in the intervention group was $33.6 \pm 6.2$ years, and the mean disease duration was $6.6 \pm 4.5$ years. In the control group, the 
mean age of the participants was $30.7 \pm 5.2$ years, and the mean disease duration was $7.9 \pm 5.3$ years.

Table 1. Demographic Data and Medications at Baseline ( $\mathrm{N}=13)$

\begin{tabular}{|c|c|c|}
\hline Variables & Experimental & Control \\
\hline \multicolumn{3}{|l|}{ Demographics } \\
\hline Age, mean $\pm S D$ & $33.6 \pm 6.2$ & $30.7 \pm 5.2$ \\
\hline Migraine duration, mean $\pm S D$ & $6.6 \pm 4.5$ & $7.9 \pm 5.3$ \\
\hline Gender & All female & All female \\
\hline \multicolumn{3}{|l|}{ Marital status } \\
\hline Single & 4 & 2 \\
\hline Married & 9 & 10 \\
\hline Divorced & 0 & 1 \\
\hline \multicolumn{3}{|l|}{ Education } \\
\hline $\begin{array}{l}\text { High school ( } 9 \text { - } 12 \text { years of } \\
\text { education) }\end{array}$ & 4 & 4 \\
\hline University degree (BSc) & 7 & 6 \\
\hline $\begin{array}{l}\text { Postgraduate university degree } \\
\text { (Masters' degree or PhD) }\end{array}$ & 2 & 3 \\
\hline \multicolumn{3}{|l|}{ Medications, N (\%) } \\
\hline \multicolumn{3}{|l|}{ Prophylactic medication } \\
\hline Beta-blockers & $3(23)$ & $2(15)$ \\
\hline Tricyclic antidepressants (TCAs) & $3(23)$ & $3(23)$ \\
\hline $\begin{array}{l}\text { Anticonvulsants (valproate and } \\
\text { topiramate) }\end{array}$ & $0(0)$ & $1(8)$ \\
\hline $\begin{array}{l}\text { Serotonin-norepinephrine } \\
\text { reuptake inhibitors (SNRIs) }\end{array}$ & $3(23)$ & $0(0)$ \\
\hline \multicolumn{3}{|l|}{ Abortive medication } \\
\hline $\begin{array}{l}\text { Nonsteroidal antiinflammatory } \\
\text { drugs (NSAIDs) }\end{array}$ & $2(15)$ & $2(15)$ \\
\hline Codeine & $1(8)$ & $2(15)$ \\
\hline Triptans and ergots & $1(8)$ & $3(23)$ \\
\hline
\end{tabular}

The findings are presented in Tables 2 and 3. In Table 2 , descriptive statistics including frequency, duration, and severity of headaches in the pretest, posttest, and followup stages are presented for 26 women with migraine. Based on the results, headache frequency was $10.63 \pm 6.16$ and $10.81 \pm 4.56$ in the experimental and control groups in the pretest, respectively. After the intervention, headache frequency decreased to $4.27 \pm 3.01$ in the experimental group in the posttest stage, while it almost remained unchanged in the control group $(10.27 \pm 3.21)$.

Evidently, headache frequency decreased significantly in the experimental group from the pretest to the posttest stage, which indicates the lower frequency of headache after MBCT. However, headache frequency remained al- most constant in the control group. The same pattern was observed in the duration and severity of headaches. Ultimately, headache frequency, duration, and severity decreased in the experimental group in the posttest stage, which shows that headaches are less frequent, shorter, and less severe after MBCT.

As presented in Table 3, covariance analysis showed that MBCT is effective in reducing headache frequency ( $P$ $=0.001<0.05)$, duration $(P=0.001<0.05)$, and severity $(P$ $=0.001<0.05)$ in women with migraine. In other words, participants in the experimental group reported a significant difference in improving symptoms in the posttest stage, compared to the control group.

\section{Discussion}

Based on the results, we can infer that MBCT reduces the frequency, duration, and severity of headache in women with migraine. To develop a new approach to prevent depressive relapses, Segal, Teasdale, and Williams first tried to understand the ways in which this type of vulnerability is developed and maintained and to determine particular processes of the mind which may reverse it. Essentially, they asked 2 questions: "What is the basis of increased vulnerability to depressive relapse?" and "What are the skills developed through CBT during an episode of depression which reduce long-term vulnerability to relapse?" (24).

Patients living with chronic pain frequently experience physical sensations of pain, accompanied by catastrophic thinking, which negatively impacts their emotional experience and activity and reduces their quality of life (25). Mindfulness has been theoretically and empirically associated with psychological wellbeing. The components of mindfulness, specifically awareness and nonjudgmental acceptance of moment-to-moment experience, provide potential protection against common forms of psychological manifestations, such as anxiety, rumination, worry, fear, anger, devastation, suppression, and avoidance (26).

In the therapeutic context, by teaching specific skills and techniques, MBCT encourages patients to see the arising of oneself as a momentary response to conditions, to suffer, and to accept thoughts as an event occurring in the mind rather than a truth defining the self. Therefore, mindfulness can change attitudes or relations to thoughts, as they are less likely to influence subsequent feelings and behaviors $(27,28)$.

Kabat-Zinn suggests that the feeling of suffering and anxiety-related thoughts without judgment help the person understand that these are only thoughts and not an indication of truth or reality; they must not necessarily cause 
Table 2. Descriptive Statistics in the Pretest, Posttest, and Follow-Up Stages ( $\mathrm{N}=13)$

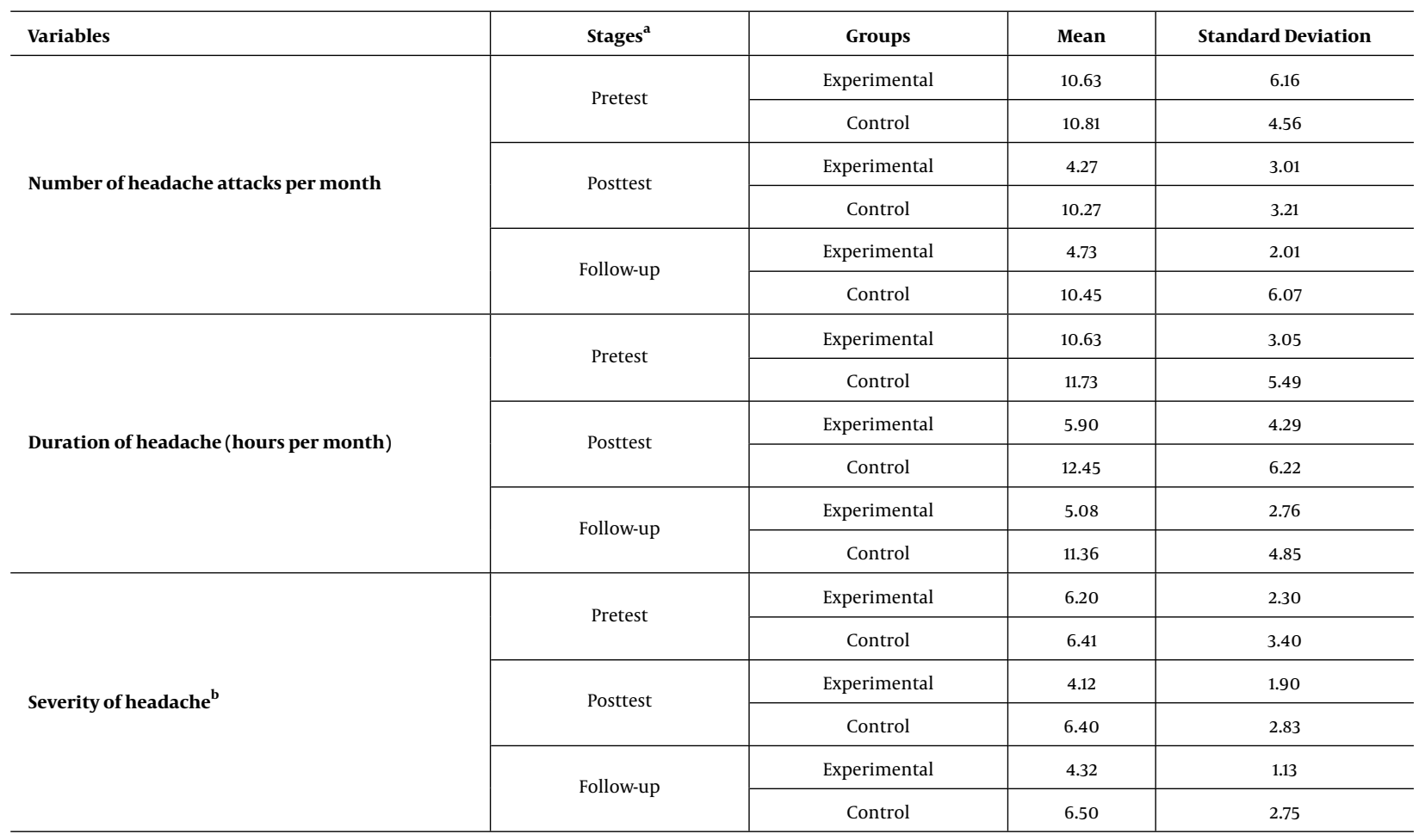

${ }^{\text {a }}$ Pretest and posttest analyses were performed 1 month before and after the intervention, respectively, and follow-up was performed 2 months after the posttest. ${ }^{\mathrm{b}}$ Headache severity was based on an 11-point Likert scale ( 0 , no pain to 10 , the worst pain)

Table 3. Covariance Analysis in the Posttest Stage

\begin{tabular}{|c|c|c|c|c|c|}
\hline Variables & Groups & Mean Square & Degree of Freedom & $\mathbf{F}$ & PValue \\
\hline \multirow{2}{*}{ Number of headaches } & Experimental & 183 & \multirow{2}{*}{1} & \multirow{2}{*}{63.7} & \multirow{2}{*}{0.001} \\
\hline & Control & 22 & & & \\
\hline \multirow{2}{*}{ Duration of headache, $h$} & Experimental & 144 & \multirow{2}{*}{1} & \multirow{2}{*}{26.4} & \multirow{2}{*}{0.001} \\
\hline & Control & 110 & & & \\
\hline \multirow{2}{*}{ Severity of headache } & Experimental & 27 & \multirow{2}{*}{1} & \multirow{2}{*}{15.9} & \multirow{2}{*}{0.001} \\
\hline & Control & 6.5 & & & \\
\hline
\end{tabular}

one to escape or show avoidance behaviors. Therefore, repeated exposure to sensations of pain with a nonjudgmental attitude or awareness may lead to a cutback in emotional responses (14).

Also, Linehan suggests that observing thoughts and emotions and using descriptive labels help one understand that these thoughts and emotions are not accurate indications of reality; for instance, the feeling or thought of guilt is not always true. General logic of using cognitivebehavioral methods in treating headache originates from observing the way people encounter daily life stress, which can initiate, intensify, or prolong headaches and increase comorbid disabilities and anxiety (29).

On the other hand, pain is a complicated mental phenomenon, and each individual has a different experience of it. Beliefs about pain, evaluations, and confrontation affect the way one experiences pain. One of the important cognitive structures in this area is the patient's belief in self-efficacy, i.e., the person's control over pain (30). Group MBCT increases self-efficacy among patients to confront daily stress and therefore decreases headache frequency in patients with migraine (19). 
In a separate study by Day and colleagues, published in February 2014, two experimental $(n, 36)$ and control groups (n, 24) used MBCT for alleviating headache pain. The results demonstrated that MBCT is a relatively safe, easy-access intervention for patients; it is also effective in dampening headaches. They also noted that those who received MBCT showed higher self-efficacy $(P=0.02 ; d, 0.82)$ and increased capacity of pain acceptance $(\mathrm{P}=0.02 ; \mathrm{d}, 0.82)$ (18).

Another study published in January 2014 on 21 participants at the University of Alabama (Kilgo Headache Clinic) showed $\geq 50 \%$ improvement in pain intensity and/or pain interference in 14 patients and $<50 \%$ improvement in 7 patients. They deduced that cognitive changes during and after MBCT are major determinants of headache pain treatment (19).

The results of previous reviews have consistently shown that adopting a psychological approach (e.g., MBCT) can be more effective in improving the symptoms rather than relying on medications alone in some patients with chronic pain. In this research, collaboration between patients and therapist or "working alliance" was satisfactory, and therapists tried to be more supportive to overcome the patients' problems and improve their outcomes.

Although the present study is consistent with previous research regarding the effectiveness of mindfulness in controlling pain, there are several limitations to be considered. While the main purpose of this study was to evaluate the effectiveness of MBCT (focused on relieving pain) in women with migraine, negligence of comorbid depression and anxiety (common comorbidity of migraine) may be a limitation, which results in increased error variance within groups. To overcome this limitation, ANCOVA test was applied to increase the statistical power by decreasing the error variance within groups.

Another shortcoming of this study is the limited number of patients with chronic migraine, who should be more deeply studied in future research due to the disabling nature of this condition. Finally, it should be noted that this study had a cross sectional design and a small sample size; also, male patients were excluded, and the duration of follow-up was short (3 months). Based on the results of the current study, it is necessary to perform further research in interdisciplinary areas of psychological and physical diseases considering the effectiveness of MBCT in controlling pain of migraine headaches.

\section{Acknowledgments}

We would like to thank all the people who contributed to this study in some way. In particular, we extend our grat- itude to Ms. Jabbari, Ms.Ghorbani and the staff of the Iranian center of neurological research.

\section{Footnote}

Financial Disclosure: The authors declare no financial interests related to the materials of this manuscript.

\section{References}

1. Headache Classification Committee of the International Headache S. The International Classification of Headache Disorders, 3rd edition (beta version). Cephalalgia. 2013;33(9):629-808. doi: 10.1177/0333102413485658. [PubMed: 23771276].

2. Ebell MH. Diagnosis of migraine headache. Am Fam Physician. 2006;74(12):2087-8. [PubMed: 17186716].

3. Lipton RB, Stewart WF, Diamond S, Diamond ML, Reed M. Prevalence and burden of migraine in the United States: data from the American Migraine Study II. Headache. 2001;41(7):646-57. doi: 10.1046/j.15264610.2001.041007638.x. [PubMed: 11554952].

4. Steiner TJ, Stovner LJ, Dua T, Birbeck GL, Jensen R, Katsarava Z, et al. Time to act on headache disorders. J Headache Pain. 2011;12(5):501-3. doi: 10.1007/s10194-011-0368-7. [PubMed: 21874562].

5. Stovner L, Hagen K, Jensen R, Katsarava Z, Lipton R, Scher A, et al. The global burden of headache: a documentation of headache prevalence and disability worldwide. Cephalalgia. 2007;27(3):193-210. doi: 10.1111/j.1468-2982.2007.01288.x. [PubMed: 17381554].

6. Holland S, Silberstein SD, Freitag F, Dodick DW, Argoff C, Ashman E, et al. Evidence-based guideline update: NSAIDs and other complementary treatments for episodic migraine prevention in adults: report of the Quality Standards Subcommittee of the American Academy of Neurology and the American Headache Society. Neurology. 2012;78(17):1346-53. doi: 10.1212/WNL.ob013e3182535doc. [PubMed: 22529203].

7. Loder E, Burch R, Rizzoli P. The 2012 AHS/AAN guidelines for prevention of episodic migraine: a summary and comparison with other recent clinical practice guidelines. Headache. 2012;52(6):930-45. doi: 10.1111/j.1526-4610.2012.02185.x. [PubMed: 22671714].

8. Nash JM, Thebarge RW. Understanding psychological stress, its biological processes, and impact on primary headache. Headache. 2006;46(9):1377-86. doi: 10.1111/j.1526-4610.2006.00580.x. [PubMed: 17040334].

9. Srikiatkhachorn A, Phanthumchinda K. Prevalence and clinical features of chronic daily headache in a headache clinic. Headache. 1997;37(5):277-80. doi: 10.1046/j.1526-4610.1997.3705277.x. [PubMed: 9195765].

10. Nash JM, Park ER, Walker BB, Gordon N, Nicholson RA. Cognitivebehavioral group treatment for disabling headache. Pain Med. 2004;5(2):178-86. doi: 10.1111/j.1526-4637.2004.04031.x. [PubMed: 15209972].

11. Thorn BE, Pence LB, Ward LC, Kilgo G, Clements KL, Cross TH, et al. A randomized clinical trial of targeted cognitive behavioral treatment to reduce catastrophizing in chronic headache sufferers. $J$ Pain. 2007;8(12):938-49. doi: 10.1016/j.jpain.2007.06.010. [PubMed: 17690017].

12. Penzien DB. Stress management for migraine: recent research and commentary. Headache. 2009;49(9):1395-8. doi: 10.1111/j.15264610.2009.01478.x. [PubMed: 19549159].

13. Rains JC, Penzien DB, McCrory DC, Gray RN. Behavioral headache treatment: history, review of the empirical literature, and methodological critique. Headache. 2005;45 Suppl 2:S92-109. doi: 10.1111/j.15264610.2005.4502003.x. [PubMed: 15921506]. 
14. Kabat-Zinn J. Full Catastrophe Living: Using the Wisdom of Your Body and Mind to Face Stress, Pain, and Illness. New York,: Delacorte Press; 1990.

15. Pradhan EK, Baumgarten M, Langenberg P, Handwerger B, Gilpin AK, Magyari T, et al. Effect of Mindfulness-Based Stress Reduction in rheumatoid arthritis patients. Arthritis Rheum. 2007;57(7):1134-42. doi: 10.1002/art.23010. [PubMed: 17907231].

16. Sephton SE, Salmon P, Weissbecker I, Ulmer C, Floyd A, Hoover K, et al. Mindfulness meditation alleviates depressive symptoms in women with fibromyalgia: results of a randomized clinical trial. Arthritis Rheum. 2007;57(1):77-85. doi: 10.1002/art.22478. [PubMed: 17266067].

17. Rosenzweig S, Greeson JM, Reibel DK, Green JS, Jasser SA, Beasley D. Mindfulness-based stress reduction for chronic pain conditions: variation in treatment outcomes and role of home meditation practice. J Psychosom Res. 2010;68(1):29-36. doi: 10.1016/j.jpsychores.2009.03.010. [PubMed: 20004298].

18. Day MA, Thorn BE, Ward LC, Rubin N, Hickman SD, Scogin F, et al. Mindfulness-based cognitive therapy for the treatment of headache pain: a pilot study. Clin J Pain. 2014;30(2):152-61. doi: 10.1097/AJP.ob013e318287a1dc. [PubMed: 23446085].

19. Day MA, Thorn BE, Rubin NJ. Mindfulness-based cognitive therapy for the treatment of headache pain: A mixed-methods analysis comparing treatment responders and treatment non-responders. Complement Ther Med. 2014;22(2):278-85. doi: 10.1016/j.ctim.2013.12.018. [PubMed: 24731899].

20. Lipton RB, Buse DC, Hall CB, Tennen H, Defreitas TA, Borkowski TM, et al. Reduction in perceived stress as a migraine trigger: testing the "let-down headache" hypothesis. Neurology. 2014;82(16):1395-401. doi: 10.1212/WNL.0000000000000332. [PubMed: 24670889].

21. Sorbi MJ, Mak SB, Houtveen JH, Kleiboer AM, van Doornen LJ. Mobile
Web-based monitoring and coaching: feasibility in chronic migraine. J Med Internet Res. 2007;9(5):e38. doi: 10.2196/jmir.9.5.e38. [PubMed: 18166526].

22. Budzynski TH, Stoyva JM, Adler CS, Mullaney DJ. EMG biofeedback and tension headache: a controlled outcome study. Psychosom Med. 1973;35(6):484-96. doi:10.1097/00006842-197311000-00004. [PubMed: 4764541].

23. Epstein LH, Abel GG. An analysis of biofeedback training effects for tension headache patients. Behav Ther. 1977;8(1):37-47. doi: 10.1016/s0005-7894(77)80119-6.

24. Teasdale JD. In: Buddhist Thought and Applied Psychological Research: Transcending the Boundaries. Nauriyal DK, Drummond MS, Lal YB, editors. London: Routledge Curzon; 2006. Mindfulness-Based Cognitive Therapy for depression.

25. Baer RA. Mindfulness training as a clinical intervention: A conceptual and empirical review. Clin Psychol Sci Pract. 2006;10(2):125-43. doi: 10.1093/clipsy.bpg015.

26. Holroyd J. Self-leadership and Personal Resilience in Health and Social Care. Learning Matters; 2015.

27. Hayes AM, Feldman G. Clarifying the construct of mindfulness in the context of emotion regulation and the process of change in therapy. Clin Psychol Sci Pract. 2006;11(3):255-62. doi: 10.1093/clipsy.bph080.

28. Witkiewitz KA, Marlatt GA. Therapist's guide to evidence-based relapse prevention. Academic Press; 2011.

29. Linehan M. Cognitive-behavioral treatment of borderline personality disorder. Guilford Press; 1993.

30. French DJ, Holroyd KA, Pinell C, Malinoski PT, O’Donnell F, Hill KR. Perceived self-efficacy and headache-related disability. Headache. 2000;40(8):647-56. doi: 10.1046/j.1526-4610.2000.040008647.x. [PubMed: 10971661]. 